\title{
Influence of the Crystallization Thermal Treatment on the Structural and Electrical Properties of PZT Thin Films
}

\author{
Antonio Leondino Bacichetti Junior ${ }^{\mathrm{a} *}$, Manuel Henrique Lente ${ }^{\mathrm{a}}$, \\ Ricardo Gonçalves Mendes ${ }^{\mathrm{b}}$, Pedro Iris Paulin Filho ${ }^{\mathrm{b}}$, José Antonio Eiras ${ }^{\mathrm{a}}$ \\ ${ }^{a}$ Universidade Federal de São Carlos, Departamento de Física Grupo de Cerâmicas \\ Ferroelétricas, 13565-670 São Carlos - SP, Brazil \\ ${ }^{\mathrm{b}}$ Universidade Federal de São Carlos, Departamento de Engenharia de \\ Materiais, PGCEM, 13565-670 São Carlos - SP, Brazil
}

Received: March 25, 2003; Revised: December 12, 2003

\begin{abstract}
Different methods have been proposed in the literature to deposit PZT thin films. Among these, chemical based processes have been revealed as a promising preparation route due to their low cost processing and the facility for controlling the stoichiometry of complex systems. The objective of this work was to investigate the influence of the time and temperature of crystallization on the physical properties of the $\mathrm{Pb}\left(\mathrm{Zr}_{0.53} \mathrm{Ti}_{0.47}\right) \mathrm{O}_{3}$ thin films prepared by a hybrid method. The structural and microstructural dependence on the crystallization conditions of the PZT films were investigated by X-ray diffraction and atomic force microscopy. Dielectric and ferroelectric properties were also characterized and their behaviors were related to the structural evolution of films.
\end{abstract}

Keywords: Thin films, PZT, ferroelectrics, crystallization

\section{Introduction}

Over the last 50 years several efforts have been made in order to make digital memories from ferroelectric materials, particularly in thin film form ${ }^{1,2}$. The advantages of such devices lie in non-volatility memory, low power consumption and high speed. In the past, some disadvantages were encountered such high voltage operation. These films required more than $5 \mathrm{~V}$ to operate, which are higher than the standard voltage of "TTL" or "CMOS". Nevertheless, in recent years, many new preparation methods and techniques of deposition have been developed allowing the production of films with a wide range of thickness and grain size. However, the production of ferroelectric thin films with nanograins has revealed remarkable new features in their physical properties in relation to their bulk ceramic counterparts ${ }^{3,4}$. For instance, smaller polarization and electrical permittivity values than those observed for ceramics are very often noticed.

Undoubtedly, ferroelectric thin films based on lead zirconate titanate, $\mathrm{Pb}(\mathrm{Zr}, \mathrm{Ti}) \mathrm{O}_{3}$, have a strong impact for a large number of technological applications, including obviously ferroelectric memory devices ${ }^{1,5}$. Other methods to deposit $\mathrm{Pb}(\mathrm{Zr}, \mathrm{Ti}) \mathrm{O}_{3}$ thin films such as $\mathrm{RF}$ sputtering ${ }^{6}$ and sol gel ${ }^{7}$ have been reported. However, chemical based processes have been revealed as a promising preparation route due to their low cost processing and the facility for controlling the stoichiometry of complex systems (e.g. binary or ternary systems). Recently, it was proposed a hybrid chemical method for the preparation of $\mathrm{Pb}(\mathrm{Zr}, \mathrm{Ti}) \mathrm{O}_{3}$ (PZT) ferroelectric thin films based on oxide precursors ${ }^{8}$. This oxide precursor method is an alternative chemical method for the preparation of PZT thin films starting from the precalcinated precursor oxides. Nevertheless, even it is being a promising method, it is imperative to determine the best preparation conditions in order to produce films with good quality, thus optimizing their physical properties.

The aim of this work is to investigate the influence of time and temperature of crystallization on the physical properties of the $\mathrm{Pb}\left(\mathrm{Zr}_{0.53} \mathrm{Ti}_{0.47}\right) \mathrm{O}_{3}$ thin films prepared by the oxide precursor method. The films were crystallized through the rapid thermal annealing process in air atmosphere. The structural and microstructural dependence on the crystallization conditions of the PZT films were studied by X-ray

*e-mail: bacichetti@ polvo.ufscar.br

Articles presented at the XV CBECIMAT, Natal - RN, November de 2002. 
diffraction and atomic force microscopy, respectively. Dielectric and ferroelectric properties were also characterized and their behaviors were related to structural evolution of the films. The influences of the grain size and mechanical stresses on the ferroelectric and dielectric properties were also pointed out.

\section{Experimental}

$\mathrm{Pb}\left(\mathrm{Zr}_{0.53} \mathrm{Ti}_{0.47}\right) \mathrm{O}_{3}(\mathrm{PZT})$ thin films were prepared through a chemical method developed for Menegazzo and collaborators $^{9,10}$. It is a hybrid method based on the precalcination of oxides or carbonates followed by dissolution in acid and subsequent preparation of polymeric resin ${ }^{8}$. In order to prepare the films, precursor powder $\mathrm{Pb}\left(\mathrm{Zr}_{0.53} \mathrm{Ti}_{0.47}\right) \mathrm{O}_{3}$ was prepared by conventional mixed oxide method ${ }^{11,12}$ using commercial powders reagents $\mathrm{PbO}\left(99.9 \%\right.$ - Aldrich), $\mathrm{ZrO}_{2}$ (99.6\% - Tam) and $\mathrm{TiO}_{2}(99.8 \%$ - Vetec). Then the calcined powder was dissolved in an aqueous solution of nitric acid ( $10 \%$ of $\mathrm{HNO}_{3}$ and $90 \%$ of distillate water) under agitation and heating. After that, citric acid and ethylene glycol were added into the solution at $90{ }^{\circ} \mathrm{C}$ under continuous agitation. A transparent resin, with homogeneously distributed ions with the same composition of the precursor powder, was obtained. The experimental procedure is detailed described in a previous work ${ }^{8}$.

Films of the polymeric resin were deposited by spin coated at $4500 \mathrm{rpm}$ for $40 \mathrm{~s}$ on Pt/Si substrates. Each deposited layer was followed by a thermal treatment to remove the organic compounds. The crystallization was performed in air atmosphere through a Rapid Thermal Annealing (RTA) at different temperatures $\left(500,600\right.$ and $\left.700{ }^{\circ} \mathrm{C}\right)$ and different times (1, 5 and $10 \mathrm{~min})$. The thickness and the surface roughess of thin films were around $500 \mathrm{~nm}$ and $30 \mathrm{~nm}$, respectively, which were determined using a Perfilometer Mytutoyo 178-896D. The formation and evolution of the crystallized phases were investigated by X-ray diffraction (XRD) analysis using a Rigaku Rotaflex RU200B diffractometer with $\mathrm{CuK}_{\alpha}$ radiation, at room temperature. The microstructure was characterized employing an atomic force microscope NanoScope III from Digital.

Dielectric and ferroelectric measurements were conducted in metal-ferroelectric-metal (MFM) configurations. Platinum electrodes $(0.5 \mathrm{~mm}$ in diameter) were sputtered deposited on the thin film surface forming the MFM configuration. The frequency dependence of the electrical permittivity $\left(\varepsilon^{\prime}\right)$ and the losses ( $\left.\varepsilon^{\prime \prime}\right)$ were measured using an impedance analyzer HP 4194A in a frequency range from $1 \mathrm{kHz}$ to $1 \mathrm{MHz}$. The electrical permittivity ( $\left.\varepsilon^{\prime}\right)$ dependence on the electric bias field was measures at $10 \mathrm{kHz}$ in the same apparatus. A modified Sawyer-Tower bridge was used for ferroelectric hysteresis loops characterization at $100 \mathrm{~Hz}$. All measurements were performed at room temperature.

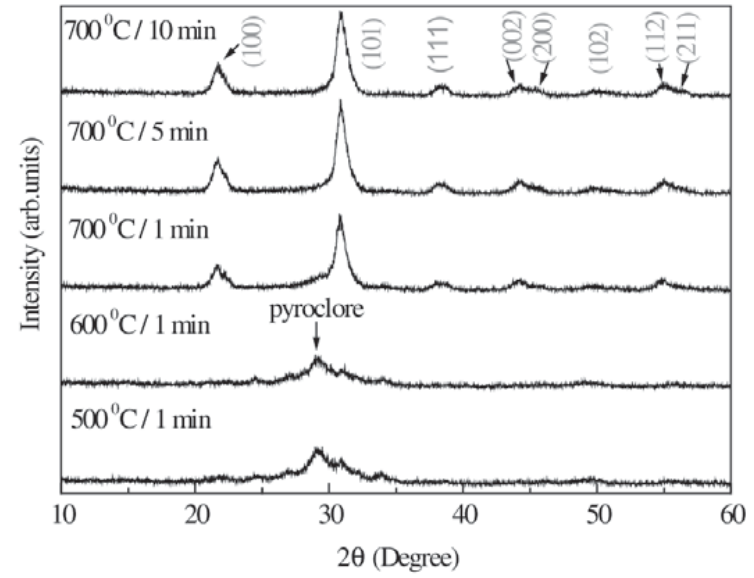

Figure 1. XRD pattern of the PZT films crystallized at different temperatures and times.

\section{Results and Discussions}

Figure 1 shows the XRD pattern of the PZT films crystallized at different temperatures and times. A remarkable crystalline structure dependence on the temperature can be viewed. The presence of pyroclore phase is remarkably noticed at lower crystallization temperatures. For the sake of simplicity, for these films only the annealing for $1 \mathrm{~min}$ is shown in Fig. 1. Nevertheless, it is verified that the perovskite phase is completely formed at $700{ }^{\circ} \mathrm{C}$ independently of the time. Moreover, it is observed that when the perovskite phase is present the crystallization time does not have strong influence on the XRD pattern. The films crystallized at $700{ }^{\circ} \mathrm{C}$ for 1,5 and $10 \mathrm{~min}$ presented basically the same diffraction patterns. Thus, it is concluded that temperature has much more influence on the crystallization process than time. In addition, Figure 1 shows that at temperatures higher than $700{ }^{\circ} \mathrm{C}$ and times longer than $5 \mathrm{~min}$ pyroclore free films are obtained. The lattice constants $a$ and $c$, calculated for the tetragonal PZT phase crystallized at $700{ }^{\circ} \mathrm{C}$ for $10 \mathrm{~min}$, were 3.99 and $4.11 \AA(c / a=1.03 \pm 0.06)$, respectively.

Figure 2 a) and (b) show the surface morphology of PZT films obtained at $700{ }^{\circ} \mathrm{C}$ for 5 and $10 \mathrm{~min}$, respectively. It is noticed that both films exhibit a homogeneous microstructure and grains are rounded-shape, which are characteristics typical of films obtained through chemical methods ${ }^{14}$. In accordance with the XRD measurements, no secondary phase was found in these films. Figure $2 \mathrm{~b}$ ) shows that the crystallization at $700{ }^{\circ} \mathrm{C} / 10 \mathrm{~min}$ induces the formation of higher grain size, between 80 and $90 \mathrm{~nm}$, and a better microstructure than that obtained at $700{ }^{\circ} \mathrm{C}$ for $5 \mathrm{~min}$. On the other hand, the results revealed that the films crystallized at 500 and $600{ }^{\circ} \mathrm{C}$ show higher concentration of agglomerates than those crystallized at $700{ }^{\circ} \mathrm{C}$, although all films 
have the same roughess $(30 \mathrm{~nm})$ independently of the temperature and time of sintering.

Figure 3 shows the ferroelectric hysteresis loops dependence on the crystallization condition. Although the XRD pattern for the films obtained at $700{ }^{\circ} \mathrm{C}$ practically did not show remarkable differences between them, the ferroelectric characterizations revealed clearly that the highest polarization values was obtained for the film crystallized for $10 \mathrm{~min}$. The remanent polarization $\left(\mathrm{P}_{\mathrm{R}}\right)$ and coercive field $\left(E_{C}\right)$ found for this films were $P_{R}=2.3 \mu \mathrm{C} / \mathrm{cm}^{2}$ and $\mathrm{E}_{\mathrm{C}}=141,0 \mathrm{kV} / \mathrm{cm}$, respectively. The results obtained for 5 min (not shown here) was intermediate between 10 and $1 \mathrm{~min}$. These results are consistent with those observed from PZT thin films produced by other chemical methods, as for example sol-gel ${ }^{14,15}$ In accordance with the XRD characterization, Fig. 3 shows that the film obtained at $600{ }^{\circ} \mathrm{C} / 10$ min does not show a ferroelectric hysteresis loop, which is clearly related to the absence of a ferroelectric crystalline phase. Identical results were obtained for the other films
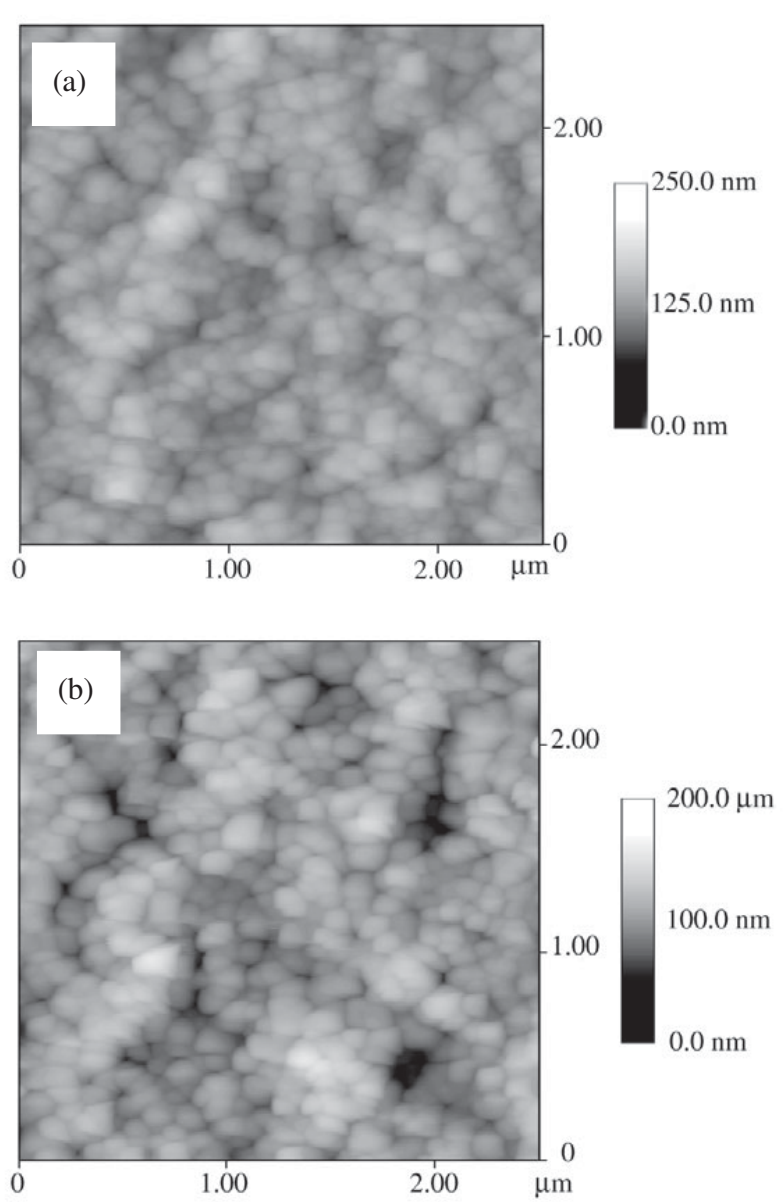

Figure 2. Surface morphology of PZT films obtained at $700{ }^{\circ} \mathrm{C}$ for: a) $5 \mathrm{~min}$; b) $10 \mathrm{~min}$.

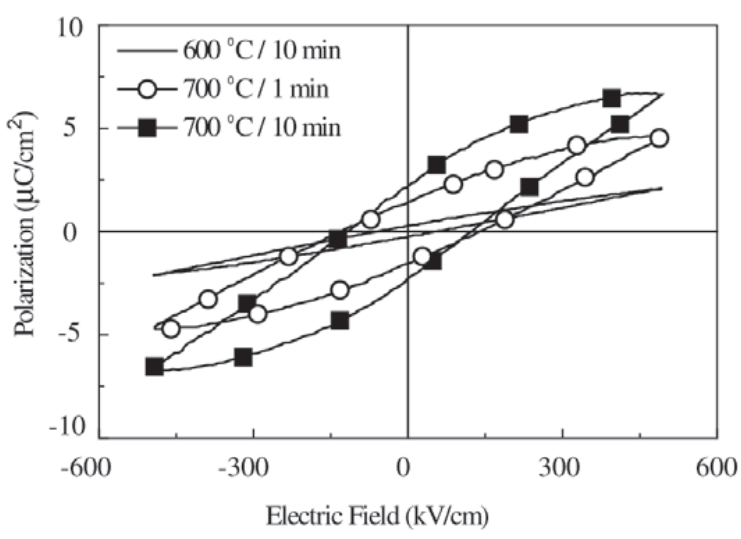

Figure 3. Ferroelectric hysteresis loops dependence on the annealing condition.
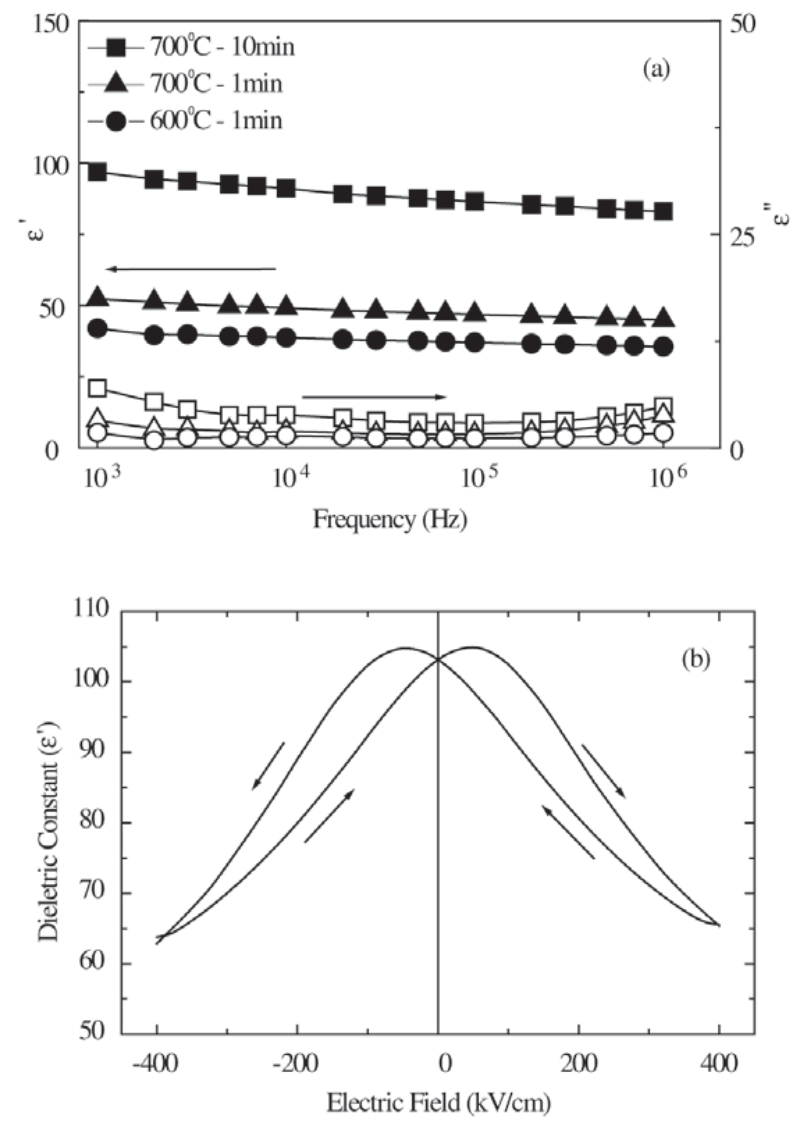

Figure 4. a) Frequency dependency of the real ( $\left.\varepsilon^{\prime}\right)$ and imaginary $(\varepsilon$ ") part of the electrical permittivity for the films annealed at different conditions; b) dielectric constant dependence on the electric bias field. 
crystallized at 600 and $500{ }^{\circ} \mathrm{C}$ regardless of crystallization time.

Figure 4 a) shows the frequency dependence of the real $\left(\varepsilon^{\prime}\right)$ and imaginary $\left(\varepsilon^{\prime \prime}\right)$ part of the electrical permittivity for the films annealed at different conditions. Similarly as observed in the ferroelectric behavior (Fig. 3), is also verified a remarkable influence of the crystallization conditions on the dielectric properties. The results show that higher temperatures and longer crystallization times furnish better values for $\varepsilon$, although an increase in $\varepsilon$ " is also noticed. Nevertheless, the increase in $\varepsilon "$, which is related to the losses, is negligible in comparison with the enhancement reached for $\varepsilon^{\prime}$. All films obtained at $600{ }^{\circ} \mathrm{C}$ showed similar results (as shown in Fig. 3 for the $600{ }^{\circ} \mathrm{C} / 1 \mathrm{~min}$ ) regardless of the crystallization time. Films crystallized at $700^{\circ} \mathrm{C}$ for 5 min showed an intermediate value related to those showed in Fig. 4. Therefore, according to the dielectric and ferroelectric results it is possible to conclude that the best condition to obtain the crystallization of films is $700{ }^{\circ} \mathrm{C} / 10 \mathrm{~min}$. Figure $4 \mathrm{~b}$ ) shows the electrical permittivity dependence on the electric bias field crystallized at $700{ }^{\circ} \mathrm{C} / 10 \mathrm{~min}$. The bias field was switched from negative to positive polarity and to the negative polarity again and its intensity was similar to that used in the ferroelectric measurements. It is observed one peak for each field polarity. The field where each peak appears has almost the same value that $\mathrm{E}_{\mathrm{C}}$, obtained from the hysteresis loops curves (Fig. 3). The nonlinear behavior of $\varepsilon$ ' $v s$. E curve has been attributed to the domain reorientation process ${ }^{16}$.

The values obtained in this work for $\mathrm{P}_{\mathrm{R}}$ and $\varepsilon$ ' are consistent with those found for nonoriented thin films deposited on random Si substrates, as will be discussed below. However, they are lower than those found for epitaxial films deposited on oriented Si substrates ${ }^{17,18}$ and bulk ceramics $^{19-20}$. This behavior can be justified based on the production of thin films in the nanometer scale. Indeed, in the nanometer scale several factors such as grain boundary ${ }^{21,22}$ and the existence of high internal stresses present in the film ${ }^{23}$ due to thermal expansion and misfit between the lattice parameter of the film and substrate became remarkable. These constraints lead to a considerable increase of internal stress in the domain structure that makes the domain motion more difficult, thus affecting the electrical properties ${ }^{21,23}$. Consequently, the values of polarization ${ }^{23}$ and electrical permittivity ${ }^{24}$ are smaller than those observed for oriented films and bulk ceramics. Although it is theoretically expected some contribution of $90^{\circ}$ domains to the electrical properties in non oriented thin films, recent works employing piezoresponse force microscopy have evidenced the possibility that only $180^{\circ}$ domain contributes to the polarization switching process, thus leading to relative low polarization values ${ }^{25}$.

\section{Conclusion}

In this work, the influence of both temperature and time of crystallization on the structural, microstructural and electrical properties was investigated. It was verified by XRD measurements that the perovskite phase is completely formed at $700{ }^{\circ} \mathrm{C}$ regardless of crystallization time. Nevertheless, based on dielectric and ferroelectric results it was concluded that the best crystallization occurs at $700{ }^{\circ} \mathrm{C}$ for $10 \mathrm{~min}$. Pyroclore phase was always predominant at crystallization temperatures lower than $700{ }^{\circ} \mathrm{C}$. The results reported in this work show the viability of the proposed chemical route, to produce PZT thin films.

\section{Acknowledgments}

The authors thank FAPESP and CNPq for the financial support.

\section{References}

1. Scott, J. F., Ferroelectrics Review, V. 1, Gordon and Breach Science Publishers, 1998.

2. Scott, J. F., McMillian, B. M., Araujo, C. A. P., Ferroelectrics, V. 93, n. 1, p. 1, 1989.

3. Randall, C. A., Kim, N., Kucera, J. P., Cao, W. W., Shrout, T. R., J. Am. Ceram. Soc., V. 81, p. 677, 1998.

4. Yan, F., Bao, P., Chan, H. L. W., Choy, C. L., Wang, Y., Thin Solid Films, V. 406, p.282, 2002.

5. Uchino, K., Ferroelectric Devices - Marcel Dekker, Inc., 2000.

6. Sreenivas, K., Sayer, M., Garret, P., Thin Solid Films, V. 172, p.251, 1989.

7. Yi, G. H., Wu, Z., Sayer, M., J. Appl. Phys., V. 64, p.2717, 1988.

8. Araújo, E. B., Eiras, J. A., J. Mat. Sci. Letters, V. 17, p.833, 1998.

9. Menegazzo, B. A., Garcia, D., Eiras, J. A., Solid State Ionics, V. 63, p. 692, 1993.

10. Menegazzo, B. A. and Eiras, J. A., J. Am. Ceram. Soc., V. 76, p.2734, 1993.

11. B. Jaffe, W.R. Cook and H. Jaffe, Piezoelectric Ceramic Academic, New ork, 1970.

12. Lente, M. H., Póvoa, J. M., Eiras, J. A., Revista Cerâmica, V. $46 \mathrm{n}^{\circ} 298$, p. 61, 2000.

13. Shao, Q., Li, A., Ling, Huiqin, Wu, D., Wang, Y., Ming, N., Materials Letters, V. 50, p.32, 2001.

14. Sedlar, M., Sayer, M., J. Appl. Phys., V. 80, p.372, 1996.

15. Yi, G., Wu, Z., Sayer, M., J. Appl. Phys., V. 64, p.2717, 1988.

16. Bar-Chaim, N., Brunstein, M., Grünberg, J., Seidman, A., J. Appl. Phys., V. 45, p.2398, 1974.

17. Zai, M. H. M., Akiba, A., Goto, H., Matsumoto, M., Yeatman, Thin Solid Films, V. 394, p. 97, 2001. 
18. Xu, F., Trolier-McKinstry, S., Ren, W., Xu, B., Xie, Z.L., Hemker, K. J., J. Appl. Phys., V. 89, p. 1336, 2001.

19. Lente, M. H., Eiras, J. A., J. Appl. Phys., V. 89, p.5093, 2001.

20. Wu, L., Wei, C., Wu, T., Teng, C., J. Phys. C: Solid State Phys., V. 16, p.2803, 1983.

21. Randall, C. A., Kim, N., Kucera, J., Cao, W.W., Shrout, T. R., J. Am. Ceram. Soc., V. 81, p.677, 1998.
22. Uchino, K., Sadanaga, E., Hirose, T., J. Am. Ceram. Soc., V. 72, p.1555, 1989.

23. Schäfer, J. D., Näfe, H., Aldinger, F., J. Appl. Phys., V. 85, p.8023, 1999.

24. Arlt, G., Pertsev, N. A., J. Appl. Phys., V. 70, p.2283, 1991.

25. Roelofs, A., Böttger, U., Waser, R., Schlaphof, F., Trogisch, S., Eng, L.M., Appl. Phys. Lett., V. 77, p. 3444, 2000. 
